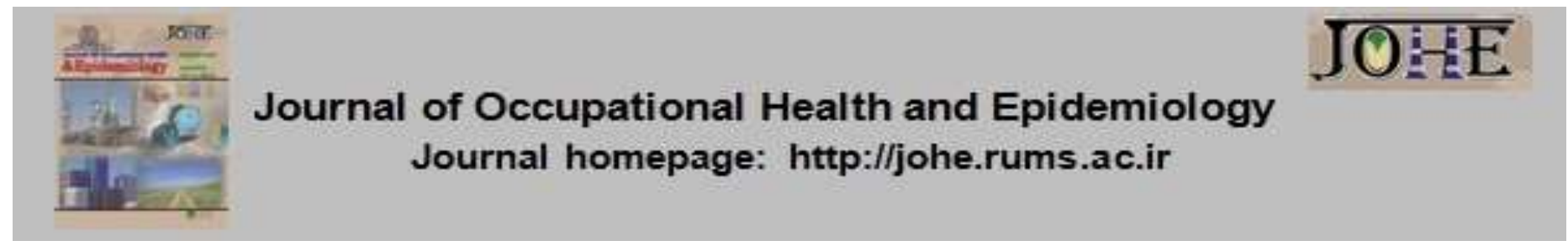

\title{
Structural Analysis of the Correlation between Occupational Stress and Quality of life in University Administrators Using a PLS Approach
}

\author{
Ahad Khalilzadeh ${ }^{1}$, Behnam Talebi ${ }^{\star}$, Assadollah Khadivi ${ }^{3}$ \\ 1- PhD Student in Educational Administration, Dept. of Educational Administration, Tabriz Branch, Islamic Azad University, Tabriz, \\ Iran. \\ 2- Assistant Prof., Dept. of Educational Administration, Tabriz Branch, Islamic Azad University, Tabriz, Iran. \\ 3- Assistant Prof., Dept. of Educational Administration, Tabriz Branch, Farhangian University, Tabriz, Iran.
}

\section{Article Info}

* Corresponding author:

Behnam Talebi,

E-mail:

btalebi1972@gmail.com

\section{Article history \\ Received: Sep 2020 \\ Accepted: Nov 2020}

10.29252/johe.9.3.180

Print ISSN: 2251-8096 Online ISSN: 2252-0902

Peer review under responsibility of Journal of Occupational Health and Epidemiology
Citation: Khalilzadeh A, Talebi B, Khadivi A. Structural Analysis of the Correlation between Occupational Stress and Quality of life in University Administrators Using a PLS Approach. JOHE 2020; 9(3):180-8.

\begin{abstract}
Background: University administrators play a key role in providing educational services to students and faculty members. This study aims to explain occupational stress (OS) in university administrators based on health-related quality of life (QoL) using a PLS approach.

Materials and Methods: The statistical population of this correlational study included all 70 managers in the field of education at Islamic Azad University of Tabriz in 2020. Based on Krejcie and Morgan's sampling table, 60 people were selected by simple random sampling. Data were collected using the revised OS questionnaire of the United Kingdom Health Safety Executive (2004) and the World Health Organization's QoL (WHOQOLBREF) questionnaire. The questionnaire of QoL included dimensions of mental health, physical health, social health, environmental health, and general health. OS questionnaire is not categorized into components. Composite reliability was 0.96 for the OS questionnaire and 0.93 for the QoL questionnaire. To test the hypotheses, structural equation modelling was employed with SPSS and PLS software.

Results: The results showed a significant negative association between QoL and its dimensions, including general health, physical health, mental health, environmental health, and social health with OS $(P<0.01)$. In addition, OS could be predicted only based on the dimensions of physical health $(P=0.02)$ and environmental health $(P=$ 0.01).

Conclusion: Paying attention to QoL in university administrators could reduce their OS and promote positive working consequences at the university.
\end{abstract}

Keywords: Occupational Stress, Quality of Life, Mental Health.

\section{Introduction}

The central role of the educational system in developing human resources and human societies in various dimensions has been well established. Although many factors are effective in developing an educational system, education managers of the university, as the most effective factors in planning for the higher education system, play a leading role in improving the quality of the education system and achieving its goals [1]. Education managers of the university are among the most important factors in providing educational services, facilitating research, planning for educational affairs, and offering guidance services to students in order to achieve goals of the higher education system in any country. In an environment in which education managers experience $\mathrm{OS}$, students and professors will be stressed, which will affect performance of the higher education system of that environment [2]. 
Stress is one of the factors exerting destructive physical and psychological effects [3]. Besides, OS is recognized as one of the most effective factors in maintaining physical and mental health among employees [4]. OS is an adaptive response to an external situation, which leads to physical, psychological, or behavioral problems among employees in an organization [5].

According to experts, general health of university staff is essential [6], being one of the most important work-related issues in modern societies [7]. However, some factors, such as working conditions, overwork, heavy responsibilities, and changing ergonomic conditions could be harmful to employees, thereby causing OS [8]. QoL is one of the important personal factors having a significant effect on OS [9]. In the meantime, QoL is a multidimensional concept affected by many factors, such as physical conditions, mental health, personal beliefs, and social relationships [10]. According to the World Health Organization, "QoL is a comprehensive concept that describes an individual's perception of various aspects in their personal status, including physical health, mental health, self-care, social relationships, and adaptation to their environment" [11]. According to the analysis performed by the World Health Organization, QoL includes the four main dimensions of physical health, mental health, social relationships, and environmental health [12]. Research results in Iran and other countries indicate that QoL and OS are interrelated. The results of the study by Jessica (2017) show that stress is a negative predictor of QoL [13]. Several studies on employees in various organizations confirm this interrelationship as well [14-20, 8, 9, 4]. Research by Yao et al (2015) [21] as well as Khan and Khurshidi (2017) [22] on university staff showed a negative relationship between these two variables. Upon reviewing available research on these two variables among university and faculty staff, one could say that such research is rare (Alves et al, 2019) [23], which deserves to receive more attention especially in Iran. Accordingly, this study aims to answer the question of 'What is the role of QoL in predicting OS in university education managers?' Given that this study aims to investigate the relationship between QoL and OS and considering the rareness of research in university education managers in terms of these two factors, the results of this study could be effective in identifying the relationship, reducing job stress, and improving QoL among university education managers.

\section{Materials and Methods}

This correlation research is based on structural equation modeling. The statistical population of this study were all 70 education managers of Islamic Azad University of Tabriz, including the Vice Chancellor for Education, Director General of Education, heads of education departments, heads of faculties, and heads of departments in academic year 2019-2020. The research sample consisted of 60 education managers who were selected through random sampling, with its size determined based on Bewick, Cheek, and Ball's (2003) table [24]. Based on this table, to estimate the sample size according to previous correlation studies, the expected correlation rate of $(R=0.25)(P=0.05)$, and a two-tailed hypothesis were selected. According to values mentioned above and based on values of the critical correlation coefficient distribution Table, the sample size was set at 60 . To test the hypotheses, structural equation modeling and the partial least squares (PLS) method were used. The inclusion criteria included being a faculty or staff member at Islamic Azad University of Tabriz and having a managerial position in 2020. In addition, the subjects were free to leave the study at any time. Two questionnaires used for data collection in this study included:

QoL Questionnaire: To measure QoL, the short form of the questionnaire presented by the World Health Organization (1989) (WHOQOL-BREF) was used, which included 4 dimensions of physical health ( 7 items), mental health ( 6 items), social relationships (3 items), environmental health (8 items). In addition general health measures by 2 items. This questionnaire has been used in many studies on QoL, including those of Hosseini Amin et al (2016) [25] and Khoshnoodi et al (2017) [26]. Nejat et al (2006) [27] in their research, by translating and standardizing this questionnaire as well as Iranian psychometrics, concluded that structural factors of this tool had acceptable validity and reliability in healthy and sick groups. They estimated that reliability of this questionnaire was $0.77,0.77,0.75$, and 0.84 for the dimensions of physical health, mental health, social health, and environmental health, respectively, and added that the discriminate validity of this questionnaire was acceptable in all areas and general health [27]. Hosseinkhani and Talebi (2020) confirmed the validity of this tool for the same dimensions using first and second order confirmatory factor analysis. Accordingly, the factor value was higher than 0.4 for all four dimensions as well as general health [28]. The composite reliability of this questionnaire 
was 0.93 in the present study using PLS software, and its reliability was 0.91 according to the Cronbach's alpha formula. This 5-point Likert scale questionnaire was answered by managers in a self-reported manner. For each item, point 5 indicates high health, and point 1 indicates low health.

OS Questionnaire: The OS questionnaire has 35 questions. This questionnaire has been compiled by the United Kingdom Health Safety Executive (2004) [29] and translated by Azad Marzabadi and Gholami Fesharaki (2010) [30]. In addition, its reliability was estimated to be 0.78 , and its validity was confirmed by content and structure validity. Accordingly, results of their research showed that reliability and validity of the questionnaire were acceptable, and its reliability coefficient was 0.78 based on Cronbach's alpha [30]. In the present study, the composite reliability of this questionnaire using PLS software was 0.96 , and its reliability based on the Cronbach's alpha formula was 0.96 . Managers answered this questionnaire on a 5point Likert scale. Accordingly, points 5 and 1 indicated the highest and lowest amounts of stress for each item, respectively.
This study has been extracted from a doctoral thesis at Islamic Azad University of Tabriz under code 1024851978569711398162259049; accordingly, ethical requirements were met, informed consent forms were obtained from the research sample, and confidentiality of respondents' information was ensured in this study.

\section{Results}

In terms of the education level, $73.3 \%$ of the research sample had a doctoral degree that was the highest frequency. Accordingly, the frequencies of a master's degree and a bachelor's degree were $20 \%$ and $6.7 \%$, respectively. In terms of age, the 41-50 year age group accounted for $56.7 \%$ of the sample size with the highest frequency, the age group of over 50 had the frequency of $31.7 \%$, the $31-40$ year age group had the frequency of $10 \%$, and the $20-30$ year age group accounted for $1.7 \%$ of the sample size. In addition, in terms of gender, $76.7 \%$ of the respondents were male, and $23.3 \%$ of them were female (Table 1).

Table 1. Demographic characteristics of education managers

\begin{tabular}{cccc}
\hline \multicolumn{2}{c}{ Demographic characteristics } & $\mathbf{N}$ & $\mathbf{P} \%$ \\
\hline \multirow{3}{*}{ Age } & $\mathbf{2 0 - 3 0}$ year age group & 1 & 1.666 \\
\cline { 2 - 4 } & $\mathbf{3 1 - 4 0}$ year age group & 6 & 10 \\
\cline { 2 - 4 } & $\mathbf{4 1 - 5 0}$ year age group & 34 & 56.667 \\
\cline { 2 - 4 } & Over 50 year age group & 19 & 31.667 \\
\cline { 2 - 4 } Gender & Male & 46 & 76.667 \\
\cline { 2 - 4 } & Female & 14 & 23.333 \\
\cline { 2 - 4 } Education level & $\mathbf{P h D}$ & 44 & 73.333 \\
& $\mathbf{M A}$ & 12 & 6.667 \\
\cline { 2 - 4 } & $\mathbf{B A}$ & 4 & 20 \\
\hline
\end{tabular}

According to data in Table 2, the mean QoL of education managers is $110.03 \pm 15.55$, and they have high QoL. Besides, the mean OS is $65.91 \pm$
23.64, being lower than average. In addition, the status of the education managers in terms of Qol components is higher than average.

Table 2. Descriptive indicators of quality of life and occupational stress in education managers

\begin{tabular}{cccc}
\hline Variable & M \pm S.D & Min & Max \\
\hline Quality of life & $110.03 \pm 15.55$ & 82 & 130 \\
\hline General health & $8.3 \pm 1.58$ & 4 & 10 \\
\hline Physical health & $29.28 \pm 4.52$ & 19 & 35 \\
\hline Mental health & $25.35 \pm 3.93$ & 16 & 30 \\
\hline Environmental health & $34.11 \pm 5.07$ & 23 & 40 \\
\hline Social health & $12.98 \pm 2.3$ & 8 & 15 \\
\hline Occupational stress & $65.91 \pm 23.64$ & 35 & 102 \\
\hline
\end{tabular}

Upon examining the relationships between the variables, the results of the Pearson's correlation test showed a significant negative relationship between QoL and its dimensions, including general health, physical health, mental health, social health, and environmental health, with OS $(\mathrm{P}<$ 
0.01). Upon testing the research hypotheses, structural equation modeling showed that OS could be highly predicted only based on physical health and environmental health. The fit of structural equation modeling, based on convergent validity indices, the factor load of the items in the measurement model, the corrected coefficient of determination, the predictive power of the model in evaluating structural modeling, and suitability of the overall model, was considered and approved. Upon using PLS software to analyze the data, if the value of the factor load for the items was higher than 0.4 , it would confirm validity of the items in measuring the variable; if the value of the significance level of the path coefficients was less than 0.05 , it would indicate significance of the relationship between the variables. Q2 shows the predictive power of the model. The coefficient of determination indicates the prediction power of the criterion variable based on the predictor variable. A coefficient of determination over 0.67 indicates high predictability. In addition, goodness of fit (GoF) was developed as an overall measure of the model fit for PLS-Structural Equation Modeling. Accordingly, a prediction power value (Q2) over 0.35 indicates a high predictive power, and a model fit (GOF) over 0.25 indicates a favorable model fit [31]. The SRMR is defined as the difference between the observed correlation and the model's implied correlation matrix. It makes the assessment of the average magnitude of discrepancies between observed and expected correlations possible, as the absolute measure of the fit criterion for the model. A value less than 0.10 or 0.08 is considered a good fit. Henseler et al (2014) introduced the SRMR as a goodness of fit measure for PLS-SEM that would be used to avoid model misspecification [32]. The value of $\mathrm{T}$ in structural equation modeling indicates the significance of the path coefficient between the variables, the value of which being at least 1.96 in the test of the two-tailed hypothesis. If the value of $\mathrm{T}$ was higher than 1.96, the relationship between the two variables would be confirmed. Accordingly, the factor load of all items is higher than 0.4 , being valid; the value of the adjusted coefficient of determination is 0.91 , being strong; the prediction value is equal to 0.39 , being above 0.35 and strong; and the good of fitness value of the model is 0.3 , being above 0.25 and above average, indicating the model has a good fit. The results are presented in Table 2 and Figs. 1 and 3.

Based on the results of the PLS regression test (Table 2), the model fit indices show that both measurement models, i.e. structural and total models of the research, have a good fit.

Table 3. Results of partial least squares regression regarding occupational stress prediction and the model fit

\begin{tabular}{|c|c|c|c|c|c|c|c|}
\hline Model fit & Variable & EH & GH & MH & PH & $\mathrm{SH}$ & QL \\
\hline \multirow{2}{*}{ Measurement } & $\begin{array}{l}\text { Composite } \\
\text { reliability }\end{array}$ & 0.86 & 0.81 & 0.82 & 0.84 & 0.93 & 0.87 \\
\hline & $\begin{array}{c}\text { Path } \\
\text { coefficient }\end{array}$ & $0.47^{*}$ & 0.21 & 0.22 & $0.34^{\star}$ & 0.23 & 0.04 \\
\hline \multirow{3}{*}{ Structural } & $\begin{array}{c}\text { Adjusted } \\
\text { R-squared }\end{array}$ & \multicolumn{6}{|c|}{0.91} \\
\hline & $\mathbf{Q}^{2}$ & 0.39 & & & & & \\
\hline & $\mathbf{T}$ & $2.43^{*}$ & 1.18 & 0.92 & $1.97^{*}$ & 0.27 & 0.31 \\
\hline \multirow{2}{*}{ Total } & GOF & \multicolumn{6}{|c|}{0.3} \\
\hline & SRMR & \multicolumn{6}{|c|}{0.07} \\
\hline
\end{tabular}

$\alpha<0.05^{*}$

Fig. 1 shows $p$-values for each item in relation to the variables, as well as the path coefficients. Accordingly with table 3, the $\mathrm{p}$-value in $\mathrm{EH}$ and $\mathrm{PH}$ is lower than 0.05 and significant. Based on Fig. 1, $\mathrm{EH}$ and $\mathrm{PH}$ have an effect on $\mathrm{OS}(\mathrm{P}<0.05)$. In the study of the standard path coefficients, the direct effect of $\mathrm{PH}$ on $\mathrm{OS}$ with a path coefficient of 0.34 and a significance level of less than 0.05 , as well as the direct effect of $\mathrm{EH}$ on $\mathrm{OS}$ with a path coefficient of 0.47 and a significance level of less than 0.05 , were significant. The path coefficient of QoL, $\mathrm{GH}, \mathrm{SH}$, and $\mathrm{MH}$ with OS was not significant due to a significance level of higher than 0.05 . 


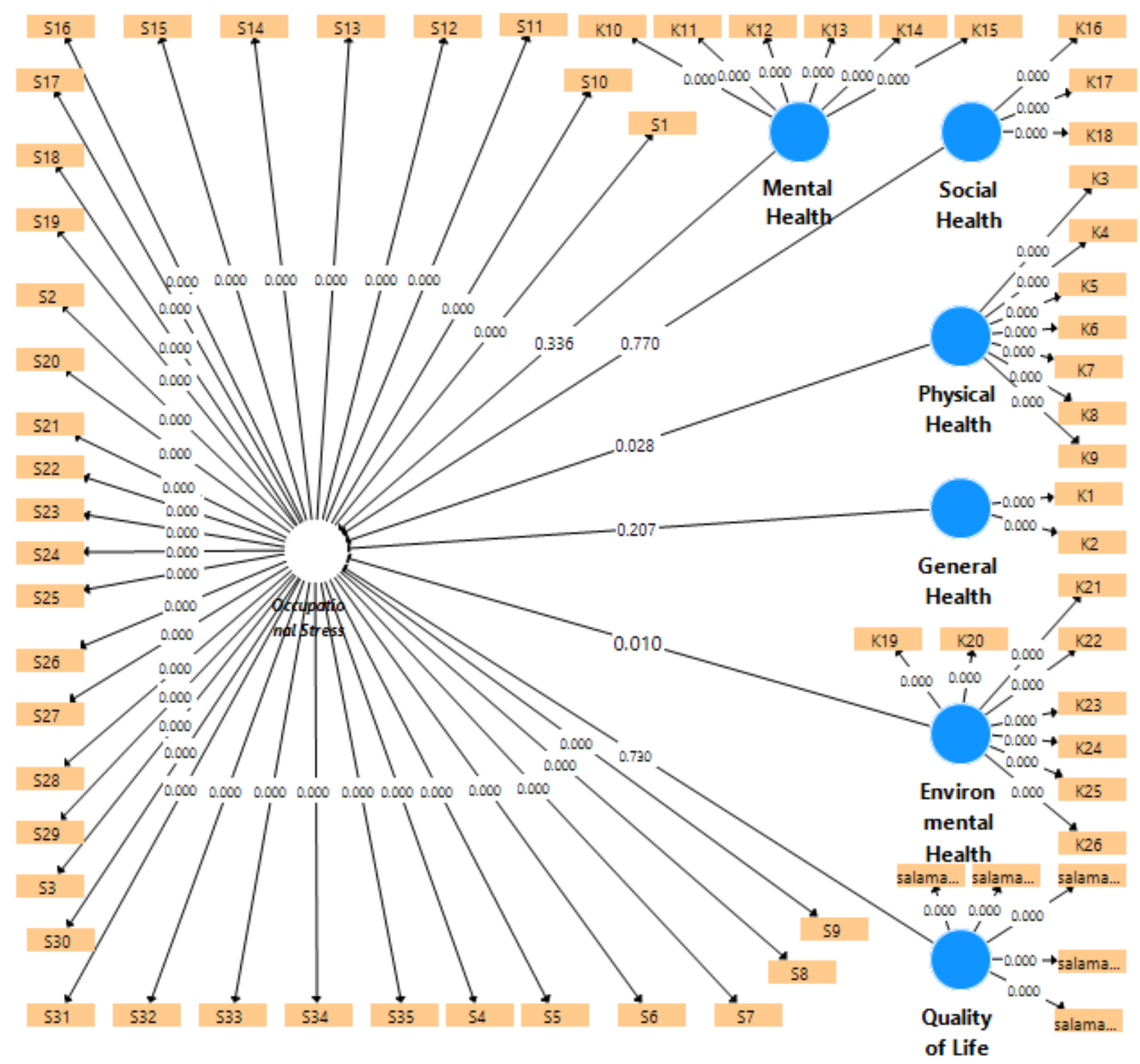

Fig. 1. P-values of occupational stress prediction based on quality of life in education managers of Islamic Azad University of Tabriz

Fig. 2 shows path and determination coefficients of each variable in OS forecast. According to Fig. 2, $\mathrm{EH}$ and $\mathrm{PH}$ have a direct impact on adjusted $\mathrm{R}$ - square of $\mathrm{OS}$ at 0.91 . Therefore, $91 \%$ of OS changes in the education managers is predictable based on their QoL. 


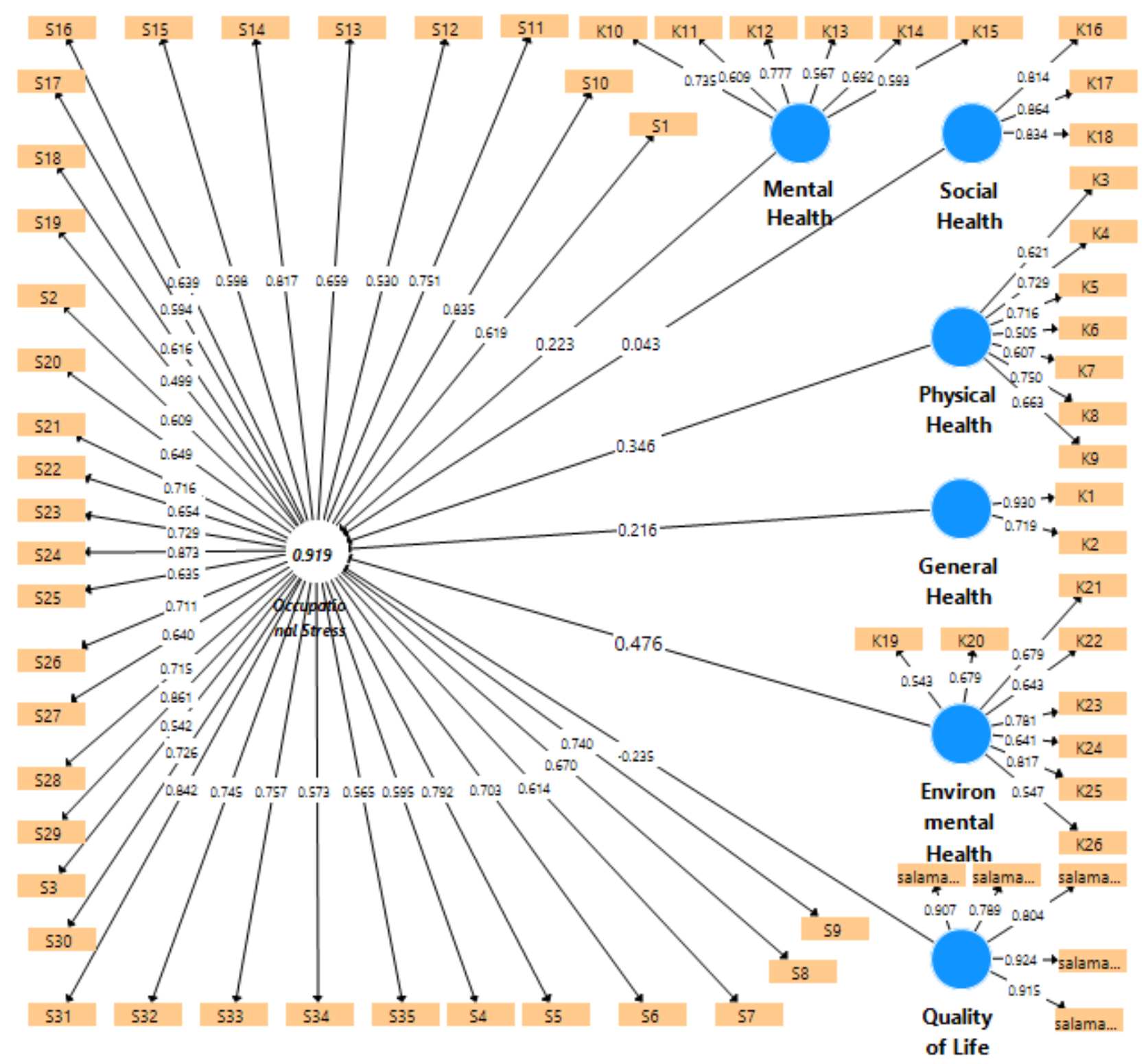

Fig. 2. Path coefficient of occupational stress prediction based on quality of life among education managers of Islamic Azad University of Tabriz

Note: S1 to S35 are OS items, and K1 to K26 are QoL items.

\section{Discussion}

The results show a significant negative relationship between QoL and its dimensions, including $\mathrm{GH}$, $\mathrm{PH}, \mathrm{MH}, \mathrm{SH}$, and $\mathrm{EH}$ with $\mathrm{OS}$. In addition, OS could be predicted based on $\mathrm{EH}$ and $\mathrm{PH}$ of QoL.

The results obtained from testing this hypothesis are consistent with those of Moshashai and Nazari (2020) [33] on the relationship between $\mathrm{GH}$ and OS, Nasiry Zarrin Ghabaee et al (2016) [14], Negahdari et al (2019) [15], Jang et al (2020) [17], $\mathrm{Li}$ et al (2019) [17], Anjara et al (2017) [19], Suleman et al (2018) [8], Hamaideh et al (2012) [9] on the relationship between QoL and all its dimensions with OS, He et al (2017) [20], Okita et al (2017) [4], Abed et al (2018) [34], Moshashai and Nazari (2020) [33] on the relationship between $\mathrm{PH}$ and OS, Yao et al (2015) [21], Khan et al (2017) [22], Mousavi et al (2020) [35], Yousefi et al (2018) [36], Pourba and Demo (2019) [37] on the relationship between $\mathrm{MH}$ and $\mathrm{OS}$, and Menati et al
(2015) [38], but the results are inconsistent with the study by Schilling et al (2019) [39] on the relationship between $\mathrm{MH}$ and with OS.

According to past research, OS and QoL are correlated. OS is a function of people's perception of $\mathrm{GH}, \mathrm{PH}, \mathrm{MH}, \mathrm{SH}$, and the environment. Accordingly, OS affects QoL and people's perception of different aspects of health, with pressures caused by OS being able to threaten their health. The results of this correlational study on university education managers show the interrelationship between these two variables as well.

OS is an unpleasant physical and emotional reaction to working conditions, which can adversely affect progress and general well-being of employees [8], thereby resulting in effort-reward imbalance [39], high-demand jobs, and the low control ability of employees in the workplace [40]. In addition, QoL is a broad concept encompassing all aspects of life, yet it is unique to everyone. Based on the results of the present research, 
university authorities are recommended to employ useful methods and strategies, such as using a favorable and positive social atmosphere, supporting collective activities, planning for sports activities, promoting public and individual health at the university, promoting professional positions at the university, and paying attention to the quality of the relationship between managers and clients to improve QoL among managers and reduce their OS. The main limitations of this study included using self-reported questionnaire tools in data collection and not using other collection tools, with the study having been limited to managers of the education department of the university. To analyze the findings of this study, one could say that QoL is a perception of health in various physical, mental, social, and environmental dimensions [41] that a person has regarding their individual and social characteristics and the quality of environmental interactions with others. Everybody can experience different perceptions [42]. The effect of this perception on people's individual and social abilities is important in optimally performing tasks and reducing mental workloads due to the feeling of imbalance between desires and the ability to control them. In the demand-job control model, according to Karasek (1979), when employees are faced with high job demands and low job control abilities, the resulting imbalance creates OS [43].

According to the results of this study, universities are recommended to help improve general health and reduce job stress among managers by providing appropriate mental and physical health facilities, thereby providing a satisfactory social environment and an invigorating physical environment, as well as reducing psychological concerns among employees and managers. The main limitations of this study included the limited statistical population, research sample, and tools used in measuring the variables.

\section{Conclusion}

The results of this study indicate a significant relationship between QoL as well as its dimensions, including $\mathrm{GH}, \mathrm{PH}, \mathrm{MH}, \mathrm{SH}$, and $\mathrm{EH}$ with OS. The variable of OS could be predicted based on $\mathrm{EH}$ and $\mathrm{PH}$ of QoL. Accordingly, one could conclude that high QoL as well as a positive perception of health dimensions in employees and managers could improve their perception of the job control ability, thereby preventing the imbalance between demands and control.

\section{Acknowledgement}

This article was extracted from a doctoral thesis at Islamic Azad University of Tabriz under code
1024851978569711398162259049. The authors would like to thank the aforementioned university for helping conduct this research.

\section{Conflict of interest: None declared.}

\section{References}

1. Talebi B, Khalilzadeh A. Explaining school principals' conflict management based on their job burnout and stress in Khoy and Chaipareh. Journal of Sociology Studies 2017; 10(34):5168.

2. Meng $Q$, Wang G. A research on sources of university faculty occupational stress: a Chinese case study. Psychol Res Behav Manag 2018; 11:597-605.

3. Robelski S, Mette J, Wirth T, Kiepe N, Nienhaus A, Harth V, et al. (Un)bounded Social Work?Analysis of Working Conditions in Refugee and Homeless Aid in Relation to Perceived Job Stress and Job Satisfaction. Int J Environ Res Public Health 2020; 17(2):601.

4. Okita S, Daitoku S, Abe M, Arimura E, Setoyama H, Koriyama C, et al. Potential predictors of susceptibility to occupational stress in Japanese novice nurses - a pilot study. Environ Health Prev Med 2017; 22(1):20.

5. Afrooz Gh, Saleh A. Stress in work environments and coping methods. 1st ed. Tehran: Al-Zahra University; 2008.

6. Hamidi Y, Shamsaei F, Beglari M, Toosi Z, Farhadian M. The Relationship between the Organizational Conflict and the Depression in the Faculty Members of Hamadan University of Medical Sciences in 2017. Iranian Journal of Ergonomics 2017; 5(3):29-35.

7. Garrosa E, Moreno-Jiménez B, Liang Y, González JL. The relationship between sociodemographic variables, job stressors, burnout, and hardy personality in nurses: an exploratory study. Int J Nurs Stud 2008; 45(3):418-27.

8. Suleman $Q$, Hussain I, Shehzad S, Syed MA, Raja SA. Relationship between perceived occupational stress and psychological wellbeing among secondary school heads in Khyber Pakhtunkhwa, Pakistan. PLoS One 2018; 13(12):e0208143.

9. Hamaideh SH. Occupational stress, social support, and quality of life among Jordanian mental health nurses. Issues Mental Health Nurs 2012; 33(1):15-23.

10. Estrella-Castillo DF, Gómez-de-Regil L. Quality of life in Mexican patients with primary neurological or musculoskeletal disabilities. Disabil Health J 2016; 9(1):127-33.

11. Wang S, Xueyan Y, Attané I. Social Support Networks and Quality of Life of Rural Men in a Context of Marriage Squeeze in China. Am J Mens Health 2018; 12(4):706-19.

12. Aaronson NK, Meyerowitz BE, Bard M, Bloom JR, Fawzy FI, Feldstein M, et al. Quality of life research in oncology. Past achievements and 
future priorities. Cancer 1991; 67(3 Suppl):83943.

13. Danilewitz JR. Quality of Life and Sources of Stress in Teachers: A Canadian Perspective. [MSc thesis]. London,Ontario, Canada: University of Western Ontario; 2017.

14. Nasiry Zarrin Ghabaee N, Talebpour Amiri F, Hosseini Velshkolaei MR, Rajabzadeh R. Quality of life and its relationship to the job stress in among nursing staff in Hospitals of Sari, in 2015. Journal of Nursing Education 2016; 5(2):40-8.

15. Negahdari A, Jadid-Milani M, Alemohammad $\mathrm{SN}$, Pishgooei SAH. The relationship between job stress and quality of work life among prehospital emergency personnel in Shiraz, 2017. Iranian Journal of Nursing Research 2019; 13(6):48-53.

16. Imani B, Karamporian A, Hamidi Y. The Relationship between Quality of Work Life and Job Stress in Employees the Foundation of Martyrs and Veterans Affairs of Hamadan. Journal of Military Medicine 2014; 15(4):253-7.

17. Jang WH, Kim DS, Park HW, Kim JH. Mental health and quality of life in firefighters working on the scene in South Korea: Focused on the capital area and the ground pro-motion area. Brain Behav 2020; 10(4):e01559.

18. Li Y, Sun X, Ge H, Liu J, Chen L. The Status of Occupational Stress and Its Influence the Quality of Life of Copper-Nickel Miners in Xinjiang, China. Int J Environ Res Public Health 2019; 16(3):353.

19. Anjara SG, Nellums LB, Bonetto C, Van Bortel $\mathrm{T}$. Stress, health and quality of life of female migrant domestic workers in Singapore: a cross-sectional study. BMC Womens Health 2017; 17(1):98.

20. He L, Zhang CL, Yang T, Lan YJ. Relationship between occupational stress, recovery experience, and physiological health of nurses in a municipal grade A tertiary hospital. Zhonghua Lao Dong Wei Sheng Zhi Ye Bing Za Zhi 2017; 35(6):425-8.

21. Yao SM, Yu HM, Ai YM, Song PP, Meng SY, Li W. Job-related burnout and the relationship to quality of life among Chinese medical college staff. Arch Environ Occup Health 2015; 70(1):27-34.

22. Khan N, Khurshid S. Workplace Stress and Employee Wellbeing: Case of Health Care Staff in UAE. European Scientific Journal 2017; 13(5):217.

23. Alves PC, Oliveira AF, Paro HBMDS. Quality of life and burnout among faculty members: How much does the field of knowledge matter? PLoS One 2019; 14(3):e0214217.

24. Bewick V, Cheek L, Ball J. Statistics review 7: Correlation and regression. Crit Care 2003; $7(6): 451-9$.

25. Hosseiniamin SN, Sayedmirzaie SM, Edrisi A. A Study of the Quality of Life and Factors Affecting It (Case Study: Citizens of Tehran).
Social Development and Welfare Planning 2016; 7(27):33-47.

26. Khoshnudi M, Safari A, Vahedian-Shahroodi M, Sadeghnejhad $\mathrm{H}$, Nejati Parvaz $\mathrm{N}$. The Relationship between Health Literacy and Quality of Life of Nurses of Hospitals of Kashmar in 2018. Journal of Health Literacy 2019; 4(1):9-17.

27. Nejat S, Montazeri A, Holakuie Naieni K, Mohammad K, Majdzadeh SR. The World Health Organization Quality of Life (WHOQOLBREF) Questionnaire: Translation and Validation Study of the Iranian Version. Journal of School of Public Health and Institute of Public Health Research 2006; 4(4):1-12.

28. Hosseinkhani N, Talebi B. The Role of School Health Nurses' Health Literacy in their Quality of Life in Health-Promoting Schools. Journal of Health_Based Research 2020; 5(4):369-82.

29. Cousins R, Mackay C, Clarke SD, Kelly C, Kelly PJ, McCaig RH. Management standards' workrelated stress in the UK: practical development. Work Stress 2004; 18(2):113-36.

30. Azad Marzabadi E, Gholami Fesharaki M. Reliability and Validity Assessment for the Hse Job Stress Questionnaire. Journal of Behavioral Sciences 2011; 4(14):291-7.

31. Esfidani MR, Mohsenin S. Structural equations based on the partial least squares approach using Smart-PLS software: educational and practical. Tehran: Mehraban Book; 2018.

32. Henseler J, Dijkstra TK, Sarstedt M, Ringle CM, Diamantopoulos A, Straub DW, et al. Common Beliefs and Reality About PLS: Comments on Rönkkö and Evermann. Organizational Research Methods 2014; 17(2):182-209.

33. Moshashaei P, Nazari J. Job Stress and Its Relationship with General Health of Employees in a Match Factory. Depiction of Health 2019; 9(4):299-308.

34. Abed M, Ansari Shahidi M, Talebi G. Investigating General Health Components and Occupation Type as Predictors of Occupational Stress in Shahid Rajaei Hospital Staff in Isfahan. Current Research in Medical Sciences 2019; 3(2):11-18.

35. Mosavi F, Nowzari V, Alam S, Zarghami M. The Relationship between Stress and Job Burnout on Mental Health of Staffs in Tehran province's Sport and Youth. Medical Journal of Mashhad University of Medical Sciences 2019; 62(4):1638-48.

36. Yoosefi N, Nasiri Hanis G, Jafari $M$. Investigating the Relationship between Organizational Climate, Occupational Stress, Job Involvement and Psychological and Spiritual Health of Prison Staff in Kurdistan Province. Organizational Behavior Studies Quarterly 2019; 7(4):281-316.

37. Purba A, Demou E. The relationship between organisational stressors and mental wellbeing within police officers: a systematic review. BMC Public Health 2019; 19(1):1286. 
38. Menati V, Niazi M, Menati R, Khazail S, Yasini A. The Relatonship between Job Stress Measured by Effort-Reward Imbalance Model and Mental Health in the Nurses Working in Government Hospitals of Ilam. Sadra Medical Sciences Journal 2015; 3(4):247-58.

39. Schilling R, Colledge F, Ludyga S, Pühse U, Brand S, Gerber M. Does Cardiorespiratory Fitness Moderate the Association between Occupational Stress, Cardiovascular Risk, and Mental Health in Police Officers? Int J Environ Res Public Health 2019; 16(13):2349.

40. Akbari J, Akbari R, Shakerian M, Mahaki B. Job demand-control and job stress at work: A cross- sectional study among prison staff. J Educ Health Promot 2017; 6:15.

41. World Health Organization. Programme on Mental Health, WHOQOL Measuring Quality of Life. Geneva, Switzerland: World Health Organization; 1997.

42. Kobayasi R, Tempski PZ, Arantes-Costa FM, Martins MA. Gender differences in the perception of quality of life during internal medicine training: a qualitative and quantitative analysis. BMC Med Educ 2018; 18(1):281.

43. Karasek RA. Job Demands, Job Decision Latitude, and Mental Strain: Implications for Job Redesign. Adm Sci Q 1979; 24(2):285-308. 